\title{
Tackling child neglect: Research, policy and evidence-based practice
}

\author{
Ruth Gardner (Ed.), 2016 \\ Jessica Kingsley Publishers, London, UK \\ ISBN 978-1-84905-662-5, pp. 367, paperback, NZ\$ 53
}

$\mathrm{D}$ ivided into three sections, Tackling Child Neglect firstly contains four contributions on the topic of "The effects of child neglect" which clarify the issues and their significance. The second section comprises four "Perspectives on child neglect" which shed light on working with neglect from different perspectives, including those of social workers, GPs, dentists and, most importantly, young people themselves. This section challenges readers to think beyond the traditional structures of social service provision and some of the constraints we (perhaps unnecessarily) accept in addressing child neglect. Part three is dedicated to "Preventing and reversing child neglect" and shares three different interventions which are currently being used and evaluated for efficacy with very promising results. The layout within the book is very clear, and it is comfortable to hold and read with good-sized fonts. There are some helpful summary pages, questions for reflection and sets of bullet points throughout which could be easily copied as discussion starters for professional development in supervision, peer review or training situations.

As a reader in Aotearoa New Zealand the UK-based context of the book is obviously somewhat different to ours in terms of services, statistics, legislation and policies; however, I did not find it difficult to relate to the issues or analyses or to imagine how the learnings from this book could be translated into our realities. Indeed, a piece of research from Aotearoa New Zealand did rate a mention (Keddell, 2011) and one of the strengths of this book is the range of studies cited and analysed in an attempt to develop a deeper understanding of the context, nature and impacts of child neglect, both short- and longer-term for individuals and families, but also for society as a whole. The lengthy reference lists at the end of each chapter made it easy to read further on points which piqued my interest.

As a social worker who is also a foster parent, the content of every chapter resonated with both my professional and personal experiences of working with children and families who are experiencing challenges with providing adequate care and "good enough" parenting. There are several chapters early on which I think would benefit every social work student, and I think that anybody working with children would gain fresh insight from reading Sarah Gorin's chapter, "Learning from children and young people about neglect."

With a solid background, in the early sections, of evidence about the significance and importance of understanding neglect, the book bridges the gap to coal-face concerns in the final section, "Preventing and reversing child neglect: An international picture," which takes time to look at three different interventions and the available evidence of their efficacy in some detail. These chapters would be of immediate interest to anyone working in child protection, family support, parenting, or mental health. The three interventions examined are the "Signs of Safety" model (which will no doubt be familiar to many already) in chapter 8, "Safecare" in chapter 9, and "Video Interactive Guidance" (VIG) in 
chapter 10 . The results of all programmes are very encouraging and warrant further investigation by practitioners not yet familiar with them, and there is also some analysis of more widely used programmes in relation to how they affect patterns of neglectful parenting which are interesting (e.g., "Triple $\mathrm{P}^{\prime}$ and "Incredible years").

A key theme reiterated throughout the book was the significance and severity of the impact of neglectful parenting on children. It is acknowledged early on that it can be very challenging to separate out the impacts of "abuse" and "neglect" but that, when this has been possible in various studies, the results show that neglect has deep and long-lasting impacts - one study concluded that "emotional unavailability on the part of a caregiver was one of the most serious forms of abuse because of its profound consequences in terms of the child's longterm development" (p. 25). Among many critical points, two stood out to me most starkly. Firstly, that children who are being neglected may find it the most difficult to recognise their own experiences as "neglect" and may find it almost impossible to articulate the things which would concern caring adults if they knew about them (pp. 140-141). A second key point was that increasing age does not mean decreasing risk from the impacts of neglect. In fact, for many young people, the effects may be cumulative. I think this is a key point for consideration in resourcing and prioritising access to services in Aotearoa New Zealand where my experience has been that situations involving younger children are often given considerably more attention and resourcing whilst older children and teenagers are sometimes thought to be resilient because they have "survived this far." The research presented in this book challenges that perspective and provides good grounds to continue to advocate for the very real, and often compounding, needs of our vulnerable teenagers.

For me, this has been a very worthwhile read with many challenges to the way we currently acknowledge and address the very significant (yet often under-estimated) impacts of neglect. It has also made me very grateful for my role in parent education through the Playcentre adult education programme and in my work with young people as a school guidance counsellor. Everything I read here reinforced the value of these endeavours and has given me more courage to assertively pursue and provide additional supports for children and their families where neglect is a feature of life at the time I meet with them.

\section{Reference}

Keddell, E. (2011). Reasoning processes in child protection decision making: Negotiating moral minefields and risky relationships. British Journal of Social Work, 41(7), 1251-1270. doi:10.1093/bjsw/bcr012 